\title{
Analyzing the Role of Anal Sphincter Pressure in Rectocele Formation
}

\author{
Süleyman Büyükaşık ${ }^{1}$, Mehmet Abdussamet Bozkurt², Selin Kapan ${ }^{1}$, Halil Alis ${ }^{1}$ \\ ${ }^{1}$ General Surgery Department, Istanbul Aydın Univercity, Istanbul; ${ }^{2}$ General Surgery Department, Bakirkoy Dr. Sadi Konuk Training and \\ Research Hospital, Istanbul, Turkey
}

Purpose: Constipation is a common entity in society with various factors in the etiology. In this study, we evaluated the role of anal sphincter pressure of patients who refer to surgery clinic with complaint of constipation.

Methods: Sixty patients who refer to surgery clinic with complaint of constipation and were diagnosed with constipation due to Rome III criteria between July 2010 and September 2014. These patients were evaluated with defecography and were divided into 2 groups based on presence of rectocele. Both groups' anal sphincter pressures were evaluated using anal manometry and findings were compared.

Results: The patients with rectocele and without rectocele using defecography were inspected with anal manometry regarding resting tone pressure, squeeze pressure, maximum squeeze pressure and simulated defecation response pressure, first sensation volume, urge sensation volume, and maximum tolerable volume. Results were compared and no significant difference was found regarding groups with rectocele and without rectocele $(P>0.05)$.

Conclusion: We have proved the hypothesis arguing that increased sphincter pressures do not play a role in the formation of rectocele by inducing an obstruction and the formation of dilation in proximal bowel, and demonstrated that the presence of rectocele is not dependent on an increase in sphincter pressures.

\section{Keywords: Rectocele; Constipation; Defecography; Anal manometry; Anal sphincter pressure}

\section{INTRODUCTION}

Anterior rectocele is the bulging of the anterior rectal wall into the vagina during defecation and straining, due to the loose or inadequate support of the endopelvic fascia located on the anal channel with additional presence of rectovaginal septum defect [1]. Although specific factors including multiple births, vaginal delivery, and extended constipation are blamed as the causes of rectocele, the accurate etiology is still unclear. Defecography is the "gold standard" for diagnosis [2]. Defecography shows the formation of

Received: Feb 2, 2019 - Revised: Sep 12, 2019 - Accepted: Sep 15, 2019 Correspondence to: Mehmet Abdussamet Bozkurt, M.D.

General Surgery Department, Bakirkoy Dr. Sadi Konuk Training and Research Hospital, Istanbul, Teyfik Saglam street 1/125, Bakirkoy/Istanbul, Turkey

Tel: +902124147205

E-mail: msametbozkurt@gmail.com

ORCID: https://orcid.org/0000-0003-3222-9363

(C) 2020 The Korean Society of Coloproctology

This is an open-access article distributed under the terms of the Creative Commons Attribution NonCommercial License (https://creativecommons.org/licenses/by-nc/4.0) which permits unrestricted non-

commercial use, distribution, and reproduction in any medium, provided the original work is properly cited. the anterior bulge of the rectal wall towards the vagina during straining and defecation. The rectum is not sufficiently emptied during defecation. Some of the radiopaque paste is left in the pocket and imaged after defecation [3]. Although rectocele is classified into 3 groups depending on the length of the bulge into the vagina $[4,5]$, the decision for surgery is made primarily considering patients' complaints. There is still confusion about whether rectocele is an etiological cause or result of constipation. Additionally, correcting the rectocele problem without establishing its accurate etiology may not ensure the elimination of the symptoms in some patients.

Another test performed to analyze the disease etiology in patients with constipation is anorectal manometry. Anorectal manometry, which is primarily used in the case of fecal incontinence, is employed to measure the sphincter pressures in patients with obstructive defecation presenting with constipation [6].

The clarification of the rectocele during straining and the simultaneous increase in anorectal squeeze pressures give rise to the thought that there is a relation between these 2 parameters. We, therefore, aim to examine this hypothesis in the present study. 
Our study is a retrospective study.

\section{METHODS}

Following the approval of the Ethics Committee of Bakırköy Dr. Sadi Konuk Training and Research Hospital (No. 2014-13-08), the patients, who applied to the General Surgery Outpatient Clinic of the hospital who underwent both defecography and anorectal manometry for the establishment of the disease etiology after the diagnosis of constipation according to Rome III criteria, were included in this retrospective study.

The female patients, who were between 18 and 80 years of age and diagnosed with constipation according to Rome III criteria but did not have a pathology (e.g., any known inflammatory bowel disease, history of colon cancer surgery, and pathologies that can obstruct discharge from the anal regions such as anal fissure or anal fistula, history of operation in the anal region, etc.) were included in the study. Undergoing both defecography and manometry was another inclusion criteria of the study. Exclusion criteria were a Rome III score $<2$, male sex, history of an anal or colorectal surgery, and the inability to tolerate either procedure.

The defecography procedures were performed by general surgeons at the Endoscopy Unit of our hospital's General Surgery Department (Istanbul, Turkey). For defecography, a paste was prepared in steel consistency by mixing $100-\mathrm{mL}$ barium with starch. Subsequently, the paste was given to the patients through the anus using a 50-mL pine-tipped syringe. The amount administered was noted when the patients described a feeling of urge. In accompany with cine-defecography, the images were obtained with the Medgate device used at our hospital and the reports were generated through the automation system.

All manometrical procedures were carried out at our Endoscopy Unit (Istanbul, Turkey), as well. We used the Sandhill Scientific device-the inSIGHT Ultima HRiM Systemmanometry (DiversiTech, Duluth, GA, USA) - for manometrical procedures. No preparation procedure was applied for the patients prior to the tests. The patients were taken to an isolated room, in which they could feel comfortable, and informed of the necessary instructions. Left lateral position was the preferred position for all patients. A 4-lumen pressure transducer catheter, which was calibrated before each procedure, was placed in the rectum after being dabbed with a lubricant product. At that phase, we measured the resting pressure; squeeze pressure and endurance squeeze pressure. In the following phase, the patients were made to cough and the same pressures were measured during effort. After the patient was asked to resume the resting position, the balloon located at the tip of the catheter was inflated. The changes in pressures were recorded following each $10-\mathrm{mL}$ air inflation. The air volume, which provoked the first desire to defecate, was determined. Subsequently, the balloon continued to be inflated, and the air volumes at which the patients felt the first desire, the first urge, higher urge and maximum toleration were respectively noted. At this stage, the balloon was completely deflated. In order to determine the rectoanal inhibitory reflex, the balloon was instantly inflated with $50-\mathrm{mL}$ air and anorectal pressures were measured. Consequently, the balloon was completely deflated once again and resting pressures were remeasured.

Recorded and measured parameters were as follows; resting pressure, squeeze pressure, endurance squeeze pressure, straining pressure, first urge, high urge, and maximum toleration volume.

The patients were divided into 2 groups according to the results of the defecography; patients diagnosed with rectocele and patients without rectocele. These 2 groups were compared by their anal manometry results. The mean, standard deviation, median, minimum, maximum, rate, and frequency values were used for descriptive statistics of the study data. The distribution of the variables was checked using the Kolmogorov-Smirnov test. The independent sample t-test and the Mann-Whitney U-test were used for the analysis of the quantitative data. Statistical analyses were carried out with IBM SPSS ver. 22.0 (IBM Corp., Armonk, NY, USA).

\section{RESULTS}

Within the scope of this study, defecography was performed for a total of 699 patients, who applied to the General Surgery Department with constipation between July 2010 and September 2014 and were diagnosed with constipation according to Rome III criteria. Two-hundred male patients were excluded from the study. Also, 12 patients with rectal prolapse and 100 patients with a history of anal or colon surgery were excluded from the study. Additionally, 247 patients, who underwent defecography but did not undergo manometry, were not included in the study. Furthermore, those patients who had defecography but could not tolerate or did not give consent to manometry, were excluded from the study. Ultimately, the study was carried out with a total of $60 \mathrm{pa}-$ tients, who admitted and underwent both defecography and manometry. The subjects were between the ages of 23 and 75 years, and the average age was $48.8 \pm 13.8$ years.

Of the defecography results of 60 patients; 30 have only anterior rectocele and 30 have normal defecographic results. The average age of the patients without rectocele was $47.8 \pm 14.1$ years while the average age of the patients with rectocele was $49.8 \pm 13.7$ years. There was no significant difference between the patients with rectocele and without rectocele regarding the age range $(\mathrm{P}>0.05)$ (Table 1).

The mean resting pressure (resting tone) was $49.1 \pm 19.6 \mathrm{mmHg}$ among patients with rectocele, whereas it was $45.8 \pm 17.8 \mathrm{mmHg}$ in patients without rectocele, and there was no significant difference between the groups $(\mathrm{P}>0.05)$. The mean squeeze pressure was $53.4 \pm 31.5 \mathrm{mmHg}$ in patients with rectocele, whereas it was $43.3 \pm 25.4 \mathrm{mmHg}$ in patients without rectocele. Therefore, no significant difference was detected between the groups $(\mathrm{P}>0.05)$. The mean endurance squeeze pressure (squeeze maximum) was 
Table 1. Comparison of age averages

\begin{tabular}{|c|c|c|c|c|c|}
\hline \multirow{2}{*}{ Variable } & \multicolumn{2}{|c|}{ Rectocele (-) } & \multicolumn{2}{|c|}{ Rectocele (+) } & \multirow{2}{*}{ P-value } \\
\hline & Mean \pm SD & Median (range) & Mean \pm SD & Median (range) & \\
\hline Age (yr) & $47.8 \pm 14.1$ & 49 (23 to 75$)$ & $49.8 \pm 13.7$ & 50 (23 to 73 ) & 0.58 \\
\hline
\end{tabular}

SD, standard deviation.

Table 2. Comparison of the 2 groups according to recorded pressures

\begin{tabular}{|c|c|c|c|c|c|}
\hline \multirow{2}{*}{ Anal manometer } & \multicolumn{2}{|c|}{ Rectocele (-) } & \multicolumn{2}{|c|}{ Rectocele (+) } & \multirow{2}{*}{ P-value } \\
\hline & Mean \pm SD & Median (range) & Mean $\pm S D$ & Median (range) & \\
\hline Resting tone & $45.8 \pm 17.8$ & 44 (16 to 100) & $49.1 \pm 19.6$ & 47 (15 to 93) & 0.493 \\
\hline Squeeze maximum & $91.4 \pm 37.0$ & 85 (37 to 180) & $116.1 \pm 51.6$ & 107 (36 to 211) & 0.071 \\
\hline Squeeze & $43.3 \pm 25.4$ & 39 (9 to 97$)$ & $53.4 \pm 31.5$ & 55 (10 to 140$)$ & 0.177 \\
\hline Simulated defecation & $-7.5 \pm 35.7$ & -7 (-93 to 48$)$ & $-18.1 \pm 25.6$ & -26 (-54 to 37) & 0.215 \\
\hline First & $89.0 \pm 37.1$ & 75 (30 to 180) & $87.3 \pm 44.4$ & 90 (30 to 180) & 0.517 \\
\hline Urge & $162.3 \pm 50.4$ & 155 (90 to 280) & $177.3 \pm 71.6$ & 160 (80 to 370) & 0.352 \\
\hline Max & $263.3 \pm 69.7$ & 250 (160 to 400) & $293.7 \pm 81.3$ & 290 (130 to 400) & 0.126 \\
\hline
\end{tabular}

SD, standard deviation.

$116.1 \pm 51.6 \mathrm{mmHg}$ in patients with rectocele while it was $91.4 \pm$ $37.0 \mathrm{mmHg}$ in patients without rectocele. Therefore, no significant difference was found between the groups $(\mathrm{P}>0.05)$. The mean straining pressure (simulated defecation response) was $-18.1 \pm 25.6 \mathrm{mmHg}$ in patients with rectocele while it was $-7.5 \pm$ $35.7 \mathrm{mmHg}$ in patients without rectocele indicating no significant difference between the groups $(\mathrm{P}>0.05)$.

The volume that proved the first desire to defecate was $87.3 \pm$ $44.4 \mathrm{~mL}$ in patients with rectocele and $89 \pm 37.1 \mathrm{~mL}$ in patients without rectocele, and there was no significant difference between these volumes $(\mathrm{P}>0.05)$. There was no significant difference between the volumes that proved the urge to defecate as it was $177.3 \pm 71.6 \mathrm{~mL}$ in patients with rectocele and $162.3 \pm 50.4 \mathrm{~mL}$ in patients without rectocele $(\mathrm{P}>0.05)$. The volume that proved the maximum urge to defecate was $293 \pm 81.3 \mathrm{~mL}$ in patients with rectocele while it was $263.3 \pm 69.7 \mathrm{~mL}$ in patients without rectocele, and therefore, there was no significant difference between the patient groups regarding the volumes provoking the maximum urge $(\mathrm{P}>0.05)$. Comparison of the 2 groups according to recorded pressures is contained in Table 2 (independent sample ttest and Mann-Whitney U-test).

\section{DISCUSSION}

Constipation is not a disease but a subjective symptom that varies from person to person [7]. Obstructive defecation syndrome, on the other hand, is the inability of a patient to fully defecate because of the presence of pathologies such as rectocele and internal mucosal intussusception resulting from loosening of the puborectal muscle and flattening of the anorectal angle during defecation.
Although some factors including obesity, multiparity, advanced age, the defect or absence of rectovaginal septum have been blamed for the etiology of rectocele-which is among the causes of obstructive defecation-the precise cause of rectocele is not yet known [8]. Rectovaginal septum is defined as a rectogenital septum and it represents an important surgical landmark for rectocele formation [9]. Obstructive defecation may result from anatomical abnormalities, which include rectocele, enterocele and internal mucosal intussusception [10].

Sarles et al. [11] reported that 3 criteria should be met to associate rectocele with anorectal outlet obstruction. First, digital vaginal maneuver should be performed during defecation. Second, defecography should prove difficult defecation. Third, defecography should enable the detection and elimination of lesions such as rectal intussusception.

Defecography is defined as a tool that physiologically and pathologically shows the morphological and functional properties of both the rectoanal region and the pelvic floor. As a result of the analysis of more than 2,500 reports generated by 2 different radiology departments in 15 years, defecography has been considered as the "gold standard" for pelvic floor diseases such as rectocele, enterocele, and intussusception $[3,12]$.

Rotholtz et al. [13] examined a total of 305 patients diagnosed with rectocele and when the sphincter pressures were compared between the groups, no significant difference was detected. We analyzed the patients with and without rectocele in this study. Similar to Rotholtz et al. [13], we found no significant difference between the sphincter pressures of the patients.

Bartolo et al. [14] conducted a study making a comparison between 49 patients with obstructive defecation and 25 healthy con- 
trols by dividing the patients with rectocele into 3 groups: puborectalis syndrome group, rectal intussusception group and anterior rectocele group. According to the manometrical assessments of those patients, there was no significant difference between the sphincter resting pressures of these 3 groups, and also, there was no significant difference between the patients and healthy controls regarding the sphincter resting pressures. Similarly, we did not find a significant difference between the patients with rectocele and without rectocele regarding the resting pressures. In that same study, the anal sphincter squeeze pressures of the patients with anterior rectocele were significantly higher as compared to the healthy controls. However, in the present study, we did not find a statistically significant difference between the groups regarding the anal sphincter squeeze pressures. However, our study population is 3 times larger than that of Bartolo et al. [14], suggesting that our results are more reliable. Whereas the average age of the patients with rectocele was 58 years in Bartolo's study, it was 49 years in our study. In the same study, the average of the maximum squeeze pressures was $276 \mathrm{mmHg}$ in patients with rectocele while we detected it to be $116.1 \pm 51.6 \mathrm{mmHg}$ in the present study.

The clinical scenario is generally accompanied with rectal intussusception and rectocele in patients indicated to have discoordinated muscle function in anal manometry [15]. One of the main questions that our study aims to answer is whether rectocele, the incidence of which reaches $80 \%$ in the general population [16], plays a role in the etiology of outlet obstruction or if it occurs as a result of outlet obstruction. However, our manometrical examinations showed no statistically significant correlation between rectocele and sphincter pressures, which implies that the presence of rectocele in these patients is an indicator of pathology independent of muscle function besides the outlet obstruction.

Regadas et al. [17] measured the external anal sphincter, internal anal sphincter, anterior upper border of the external anal sphincter and the thickness of the wall of anal channel in the study, in which they compared 17 patients with grade III rectocele with healthy individuals. Regadas et al. [17] suggested that the length of the external anal sphincter and the thickness of the anal wall were lower, but the length of the anorectal angle was higher in the patients with rectocele. It was also demonstrated that the circular muscle layer forming the internal anal sphincter was thinner in the patients with rectocele. However, there was no significant difference between the groups when they were compared considering anal resting and squeeze pressures. These results are consistent with our study. Nevertheless, the absence of a difference between pressures despite shorter external anal sphincter gives rise to the thought that the external muscular tonus has been exposed to hypertrophy.

In this study, we have proved that the hypothesis arguing that increased sphincter pressures don't play a role in the formation of rectocele by inducing an obstruction and the formation of dilation in proximal bowel, and demonstrated that the presence of rectocele is dependent on the increase in sphincter pressures. The limitation of this study is retrospective nature and small sample.

\section{CONFLICT OF INTEREST}

No potential conflict of interest relevant to this article was reported.

\section{REFERENCES}

1. Karasick S, Karasick D, Karasick SR. Functional disorders of the anus and rectum: findings on defecography. AJR Am J Roentgenol 1993;160:777-82.

2. Alabaz O. Pelvic floor disease. In: Mentes BM, Bulut T, Alabaz O, Leventoglu S, editors. Benign disease of the anorectal region. Istanbul (Turkey): Turkish Society of Colon and Rectum Disease; 2011. p. 167-87.

3. Faccioli N, Comai A, Mainardi P, Perandini S, Moore F, PozziMucelli R. Defecography: a practical approach. Diagn Interv Radiol 2010;16:209-16.

4. Murad-Regadas SM, Regadas FS, Rodrigues LV, Silva FR, Soares FA, Escalante RD. A novel three-dimensional dynamic anorectal ultrasonography technique (echodefecography) to assess obstructed defecation, a comparison with defecography. Surg Endosc 2008;22:974-9.

5. Murad-Regadas SM, Regadas FS, Rodrigues LV, Oliveira L, Barreto RG, de Souza MH, et al. Types of pelvic floor dysfunctions in nulliparous, vaginal delivery, and cesarean section female patients with obstructed defecation syndrome identified by echodefecography. Int J Colorectal Dis 2009;24:1227-32.

6. Rao SS, Azpiroz F, Diamant N, Enck P, Tougas G, Wald A. Minimum standards of anorectal manometry. Neurogastroenterol Motil 2002;14:553-9.

7. Miller LE, Ibarra A, Ouwehand AC, Zimmermann AK. Normative values for stool frequency and form using Rome III diagnostic criteria for functional constipation in adults: systematic review with meta-analysis. Ann Gastroenterol 2017;30:161-7.

8. Bozkurt MA, Kalayci MU, Gemici E, Dilege E, Alis H. Is colonic transit-time measurement valuable in the etiological evaluation of constipation? Turk J Surg 2012;28:31-3.

9. Dariane C, Moszkowicz D, Peschaud F. Concepts of the rectovaginal septum: implications for function and surgery. Int Urogynecol J 2016;27:839-48.

10. Li M, Jiang T, Peng P, Yang XQ, Wang WC. Association of compartment defects in anorectal and pelvic floor dysfunction with female outlet obstruction constipation (OOC) by dynamic MR defecography. Eur Rev Med Pharmacol Sci 2015;19:1407-15.

11. Sarles JC, Arnaud A, Selezneff I, Olivier S. Endo-rectal repair of rectocele. Int J Colorectal Dis 1989;4:167-71.

12. Rafiei R, Bayat A, Taheri M, Torabi Z, Fooladi L, Husaini S. Defecographic findings in patients with severe idiopathic chronic constipation. Korean J Gastroenterol 2017;70:39-43. 


\section{Coloproctology süleyman Büyukagalk, et al.}

13. Rotholtz NA, Efron JE, Weiss EG, Nogueras JJ, Wexner SD. Anal manometric predictors of significant rectocele in constipated patients. Tech Coloproctol 2002;6:73-6; discussion 76-7.

14. Bartolo DC, Roe AM, Virjee J, Mortensen NJ, Locke-Edmunds JC. An analysis of rectal morphology in obstructed defaecation. Int J Colorectal Dis 1988;3:17-22.

15. Lau CW, Heymen S, Alabaz O, Iroatulam AJ, Wexner SD. Prognostic significance of rectocele, intussusception, and abnormal perineal descent in biofeedback treatment for constipated patients with paradoxical puborectalis contraction. Dis Colon Rec- tum 2000;43:478-82.

16. Bozkurt MA, Surek A, Gonenc M, Kalayci MU, Alis H. Significance of defecography and the role of rectocele in constipated patients. Open J Gastroenterol 2012;2:40-4.

17. Regadas FS, Murad-Regadas SM, Wexner SD, Rodrigues LV, Souza $\mathrm{MH}$, Silva FR, et al. Anorectal three-dimensional endosonography and anal manometry in assessing anterior rectocele in women: a new pathogenesis concept and the basic surgical principle. Colorectal Dis 2007;9:80-5. 